\title{
Utilization of synthetically generated hourly wind speed data in the optimization of Wind-Batteries stand-alone systems.
}

\author{
Rodolfo Dufo-López, José L. Bernal-Agustín, Juan Lujano, José Antonio Domínguez-Navarro \\ Department of Electrical Engineering \\ Zaragoza University \\ Calle María de Luna, 3. E-50018 Zaragoza (Spain). \\ Phone: 0034 976661921, Fax: 0034976762226 \\ e-mail: rdufo@unizar.es, jlbernal@unizar.es, lujano.juan@gmail.com,jadona@unizar.es
}

\begin{abstract}
This paper shows a study of the influence of the type of wind data in the optimization of Wind-Batteries standalone systems. We have considered two types of input data for the wind speed: 1) measured wind speed hourly data for a whole year and 2) monthly average wind speed data. When using the second type of data, we generate synthetically the hourly wind speed data of the year, and we force a certain number of consecutive days of "calmness" (in this case wind speed lower than $3 \mathrm{~m} / \mathrm{s}$ ) in the month of most time of calmness (generally December or January in Zaragoza). The results show that, using monthly average wind speed data, if the number of consecutive days of forced calmness is adequate, the optimal system found by the optimization tool is the same as the one obtained using the measured wind speed hourly data. Thus, the method of generating wind speed hourly data synthetically is validated to be used in the optimization of Wind-Hybrid systems.
\end{abstract}

\section{Key words}

Stand-alone Wind-Batteries systems, generation of hourly wind speed, optimization software.

\section{Introduction}

Stand-alone Wind-Batteries systems are not very usual, as hybrid systems including Photovoltaic or Diesel are more reliable and usually lest costly than the systems that use a single source of energy [1].

The main problem in Wind-Batteries systems is the variability of wind speed. In stand-alone systems this aspect is even more important than in grid-connected systems, as wind resource is the only primary source of energy to supply the load. From one year to another the performance of a stand-alone Wind-Batteries system can change drastically, as the wind speed can be different in average values and in distribution during the year. If the electrical load to be supplied is critical, another source of energy must be added, generally Photovoltaic panels or Diesel genset, or both. Even for non-critical load, the use of hybrid systems is encouraged by many manufacturers of wind turbines.

In this work we have considered only Wind-Batteries systems (Fig. 1) to study the influence of the wind speed data in the optimization of the system. However, the conclusions obtained can be extrapolated to wind-hybrid systems, and should be taken into account in the optimization of wind-hybrid systems.

The optimization of the system is done by HOGA (Hybrid Optimization by Genetic Algorithms) software, developed by the authors [2,3].

We have considered two types of input data for the wind speed:

- Measured wind speed hourly data for a whole year.

- Monthly average wind speed data for a whole year.

Comparing the results of using one type of data or the another one, we conclude that the use of monthly average wind speed data can be correct, taking into account some considerations.

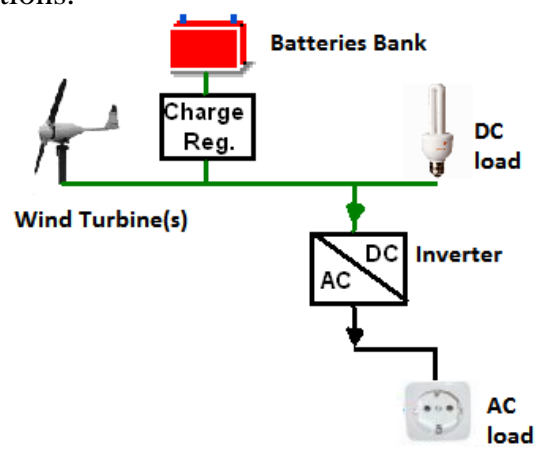

Fig 1. Wind-Batteries system.

\section{Model to generate wind speed hourly data}

If we use as input data the monthly average wind speed, we must generate hourly wind speed data so that HOGA can simulate the systems in steps of 1 hour. Different methods to generate hourly wind speed series are in the literature, some of them use ARMA models [4]. The model used by HOGA to generate synthetically wind speed hourly data is a simple model, shown in [5].

Wind speed hourly data $v(\mathrm{t})$ is calculated by equation (1):

$$
v(t)=v_{\mathrm{p}}(t)+\alpha_{\mathrm{v}}(t)
$$

Where $v_{\mathrm{p}}(t)$ is the part of wind speed which indicates the dependency of wind speeds upon the time of the day: 


$$
v_{\mathrm{p}}(t)=v_{\mathrm{n}}+\max \left[0,\left(A_{\mathrm{v}}-F \cdot\left(t-h_{\max }\right)^{2}\right)\right]
$$

Where $v_{\mathrm{n}}$ is the average night speed of the month, $A_{\mathrm{v}}$ is the amplitude, $F$ factor provides an indication of the dependency of wind speeds upon the time of the day at which speeds are measured and $h_{\max }$ is the hour of the maximum speed.

The average wind speed of the month, $v_{\mathrm{m}}$, is calculated as follows:

$v_{\mathrm{m}}=v_{\mathrm{n}}+\sqrt{\frac{A_{\mathrm{v}}}{F}} \cdot \frac{A_{\mathrm{v}}}{18}$

Usually the dependency of wind speeds upon the time of the day is unknown. Then, input data is only the wind speed of the month, $v_{\mathrm{m}}$, considering $A_{\mathrm{v}}=0$ and $v_{\mathrm{n}}=v_{\mathrm{m}}$.

The random part of the wind speed $\alpha_{\mathrm{v}}$ is calculated by equation (4), modifying the one exposed in [5].

$$
\alpha_{\mathrm{v}}(\mathrm{t})=f c_{\mathrm{v}} \cdot\left[w_{\mathrm{v}}(\mathrm{t}-1)-w_{\mathrm{m}}\right]+\left[1-f c_{\mathrm{v}}\right] \cdot\left[w_{\mathrm{v}}(\mathrm{t})-w_{\mathrm{m}}\right]
$$

Where $f c_{\mathrm{v}}$ is the correlation factor and $w_{\mathrm{v}}(\mathrm{t})$ is a random number with Weibull probability distribution of average value $w_{\mathrm{m}}=v_{\mathrm{m}} \cdot\left(1-f c_{\mathrm{v}}{ }^{2}\right)^{1 / 2}$

$$
w_{\mathrm{v}}(\mathrm{t})=\left[-\theta^{\mathrm{b}} \cdot \ln (1-\mathrm{a}(\mathrm{t}))\right]^{1 / \mathrm{b}}
$$

Where $\theta$ is the scale factor of the Weibull distribution, $b$ is the form factor and $\mathrm{a}(\mathrm{t})$ is a random number between 0 and 1 .

HOGA allows the option of forcing a certain number of consecutive days to have wind speed lower than a certain value, taking into account some consecutive days of "calmness".

\section{Wind speed data}

We have used the wind speed hourly data of years 2001 to 2009 from the Zaragoza Airport (Spanish Meteorological Agency, Agencia Estatal de Meteorología, AEMET [6]), assuming $10 \mathrm{~m}$ height.

In Table I, the average wind speed of every month, calculated from the wind speed hourly data, is shown.

Also, HOGA software compares the wind speed probability distribution with Weibull distributions with form factor from $b=1$ to 4 in 0.1 steps, and it shows the form factor that fits better [7]. HOGA also informs about the number of consecutive days of "calmness", i.e., wind speed lower than a certain value fixed by the user (in this case we consider "calmness" wind speed lower than 3 $\mathrm{m} / \mathrm{s}$, as wind turbines produce very low power), and the percentage of the time of the month in which wind speed is lower than that value. For example, in 2001, the maximum number of consecutive days with wind speed lower than $3 \mathrm{~m} / \mathrm{s}$ is 3.2 days, in December, and, in this month, $51 \%$ of time wind speed is lower than $3 \mathrm{~m} / \mathrm{s}$.

\section{Wind-Batteries system optimization.}

The Wind-Batteries system must supply a typical domestic load, located near Zaragoza, considering all the days the same load, 3630 Wh AC load in one day (Fig. 2).

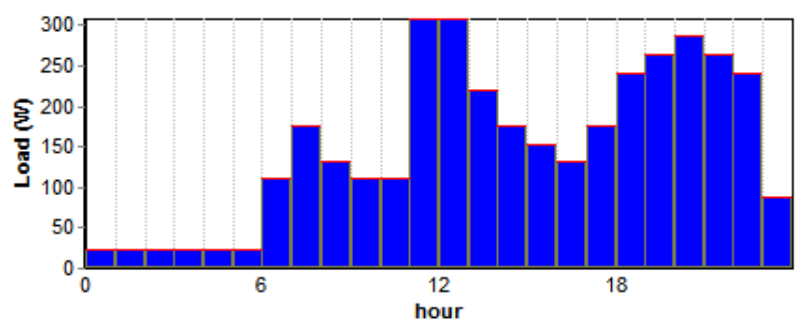

Fig. 2. Load

2 models of batteries:

- Battery 1: $444 \mathrm{Ah}, 12 \mathrm{~V}$, roundtrip efficiency $80 \%$, SOCmin 20\%, 1435 equiv. full cycles, cost $1135 €$.

- Battery2: 80 Ah, $12 \mathrm{~V}$, roundtrip efficiency $80 \%$, SOCmin 40\%, 905 equivalent full cycles, cost $200 €$.

DC voltage of the system is $48 \mathrm{~V}$, so there will be 4 batteries in serial. The maximum number of batteries in parallel allowed is 10 .

\section{3 models of wind turbines:}

- Wind turbine 1: maximum output power $400 \mathrm{~W}$ DC, $10 \mathrm{~m}$ height, acquisition cost $980 €$.

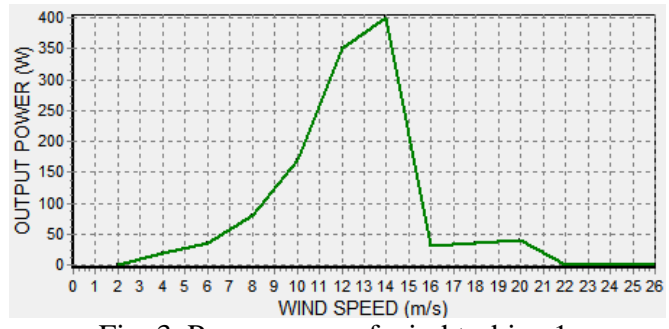

Fig. 3. Power curve of wind turbine 1.

- Wind turbine 2: maximum output power $1700 \mathrm{~W}$ DC, 10 m height, acquisition cost $4060 €$.

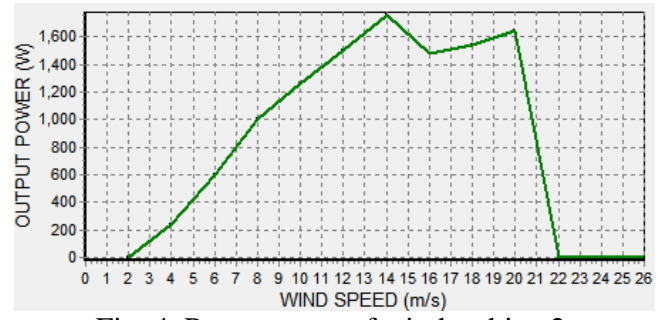

Fig. 4. Power curve of wind turbine 2. 
Table I. - Data calculated from hourly wind speed data measured in the Zaragoza Airport from AEMET.

\begin{tabular}{|c|c|c|c|c|c|c|c|c|c|}
\hline & 2001 & 2002 & 2003 & 2004 & 2005 & 2006 & 2007 & 2008 & 2009 \\
\hline JANUARY $(\mathrm{m} / \mathrm{s})$ & 4.41 & 3.56 & 6.4 & 5.5 & 5.28 & 3.73 & 3.28 & 2.85 & 3.82 \\
\hline FEBRUARY $(\mathrm{m} / \mathrm{s})$ & 5.65 & 5.45 & 5.46 & 3.38 & 5.93 & 4.89 & 3.88 & 2.4 & 4.84 \\
\hline MARCH $(\mathrm{m} / \mathrm{s})$ & 4.21 & 5.28 & 3.33 & 4.31 & 4.34 & 4.64 & 6.33 & 6.12 & 5.37 \\
\hline APRIL $(\mathrm{m} / \mathrm{s})$ & 6.33 & 4.59 & 4.33 & 5.09 & 4.83 & 4.97 & 2.68 & 4.74 & 5.55 \\
\hline MAY $(\mathrm{m} / \mathrm{s})$ & 4.27 & 6.07 & 4.65 & 3.88 & 4.48 & 4.39 & 4.72 & 3.32 & 4.68 \\
\hline JUNE $(\mathrm{m} / \mathrm{s})$ & 5.01 & 5.71 & 3.97 & 5.13 & 4.4 & 4.37 & 3.49 & 4.53 & 4.54 \\
\hline $\mathrm{JULY}(\mathrm{m} / \mathrm{s})$ & 4.27 & 4.81 & 4.14 & 4.81 & 5.24 & 4.14 & 5.1 & 4.31 & 5.15 \\
\hline AUGUST $(\mathrm{m} / \mathrm{s})$ & 3.91 & 3.9 & 2.92 & 3.87 & 5.7 & 5.98 & 5.15 & 3.94 & 4.43 \\
\hline SEPTEMBER $(\mathrm{m} / \mathrm{s})$ & 5.51 & 3.66 & 3.52 & 4.98 & 4.15 & 3.51 & 4.14 & 4.02 & 4.06 \\
\hline OCTOBER $(\mathrm{m} / \mathrm{s})$ & 2.81 & 4.63 & 3.73 & 3.07 & 3.59 & 3.24 & 4.41 & 3.57 & 4.78 \\
\hline NOVEMBER $(\mathrm{m} / \mathrm{s})$ & 6.71 & 4.63 & 2.92 & 5.04 & 4.15 & 3.1 & 5.9 & 4.82 & 3.67 \\
\hline DECEMBER $(\mathrm{m} / \mathrm{s})$ & 3.4 & 2.96 & 4.12 & 4.82 & 3.96 & 3.09 & 3.44 & 4.63 & 4.2 \\
\hline $\begin{array}{l}\text { Average wind speed of the } \\
\text { year }(\mathrm{m} / \mathrm{s})\end{array}$ & 4.69 & 4.60 & 4.12 & 4.49 & 4.66 & 4.17 & 4.38 & 4.11 & 4.59 \\
\hline Weibull factor, $\mathrm{b}$ & 1.4 & 1.4 & 1.3 & 1.3 & 1.5 & 1.3 & 1.3 & 1.3 & 1.4 \\
\hline $\begin{array}{l}\text { Maximum number of } \\
\text { consecutive days with wind } \\
\text { speed }<3 \mathrm{~m} / \mathrm{s} \text { ("calmness") } \\
\text { in month }\end{array}$ & $\begin{array}{r}3.2 \\
\text { Dec. }\end{array}$ & $\begin{array}{r}3.7 \\
\text { Dec. }\end{array}$ & $\begin{array}{r}2.3 \\
\text { Nov. }\end{array}$ & $\begin{array}{r}6 \\
\text { Dec. }\end{array}$ & $\begin{array}{r}5.7 \\
\text { Dec. }\end{array}$ & $\begin{array}{r}5.6 \\
\text { Dec. }\end{array}$ & $\begin{array}{l}3.6 \\
\text { Jan. }\end{array}$ & $\begin{array}{r}3.7 \\
\text { Dec. }\end{array}$ & $\begin{array}{r}2.7 \\
\text { Jan. }\end{array}$ \\
\hline $\begin{array}{l}\text { Percentage of time in that } \\
\text { month with wind speed }<3 \\
\mathrm{~m} / \mathrm{s}(\%)\end{array}$ & 51 & 56 & 60 & 35 & 45 & 35 & 59 & 41 & 48 \\
\hline
\end{tabular}

- Wind turbine 3: maximum output power $6500 \mathrm{~W}$ DC, $10 \mathrm{~m}$ height, acquisition cost $10020 €$.

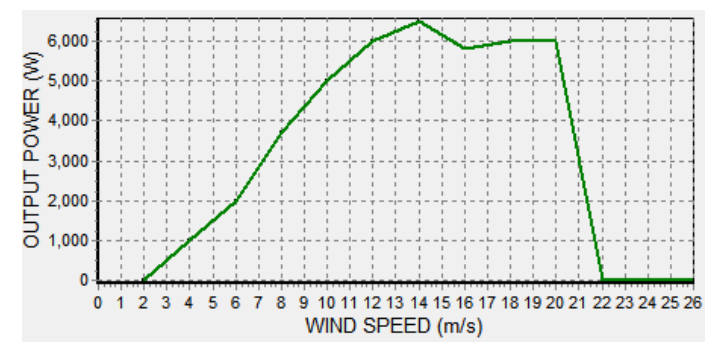

Fig. 5. Power curve of wind turbine 3.

The maximum number of wind turbines in parallel allowed is 2 .

\section{Inverter:}

500 VA, acquisition cost $400 €$, efficiency in Fig. 6.

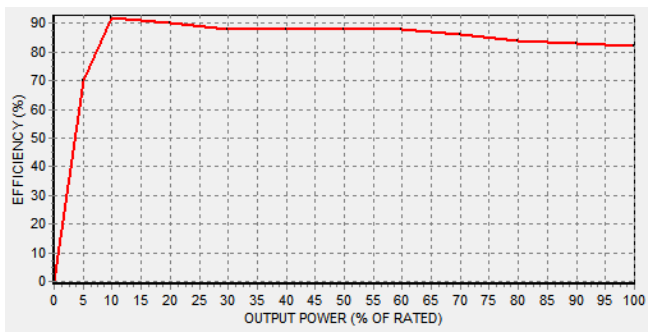

Fig. 6. Inverter efficiency.

\section{Batteries charge regulator:}

Its size is calculated for each combination of components. Acquisition cost is $30 €+4 \cdot I €$, where $I$ is the maximum input current (A).
The number of possible combinations of components is 2 models of batteries $x 10$ (batteries in parallel between 1 and 10) $x 3$ models of wind turbines $\times 2$ (wind turbines in parallel 1 or 2$)=120$ possible combinations of components. We will use the enumerative optimization method (evaluating all the possible combinations of components).

Each combination of components is evaluated: HOGA simulates the performance of every hour of the year. If the unmet load is higher than a percentage fixed by the user (we have fixed $0.1 \%$ ), that combination of components is discarded. If not, HOGA calculates the Net Present Cost (NPC) of the system. When HOGA has evaluated all the possible combinations, the optimal one is the one with lowest NPC (data considered to calculate NPC: annual nominal interest rate $4 \%$, annual inflation rate $2 \%$, system lifetime 25 years, installation cost $300 €$ $+2 \%$ of total cost).

\section{Results.}

As input data for the optimization, we have used the wind speed hourly data of each year from 2001 to 2009.

For each year, we have optimized the system to supply the load, allowing a $0.1 \%$ of unmet load in the year. We have done 11 optimizations for each year, taking into account 11 different wind speed hourly data series:

A) 1 optimization taking into account the wind speed hourly data measured of the year (AEMET).

B) 5 optimizations considering synthetically generated wind speed hourly data for the year. Each time hourly wind speed data is generated, obtaining 5 
different wind speed hourly series. These series are calculated from the average monthly wind speed data of the year and the Weibull form factor of the wind speed data of the year (Table I). A correlation factor of 0.5 has been taking into account.

C) 5 optimizations considering synthetically generated wind speed hourly data for the year. Each time hourly wind speed data is generated as in B) and, additionally, the wind speed of a certain number of consecutive days have been forced to be lower than 3 $\mathrm{m} / \mathrm{s}$ in a certain month.

If we take a look at the wind speed hourly data measured (AEMET) for each year, we can see that the effective consecutive days of "calmness" is higher than shown in Table I.

For example, in 2003 there are only a maximum of 2.3 consecutive days of wind speed lower than $3 \mathrm{~m} / \mathrm{s}$ (Table I), and it occurs in November. However, from the $2^{\text {nd }}$ to $11^{\text {th }}$ November, 2003, there are about 8 consecutive days with low wind speed (Fig. 7). So, for the calculation of the wind speed hourly series type C) we must consider 8 days of calmness instead 2.3 days.

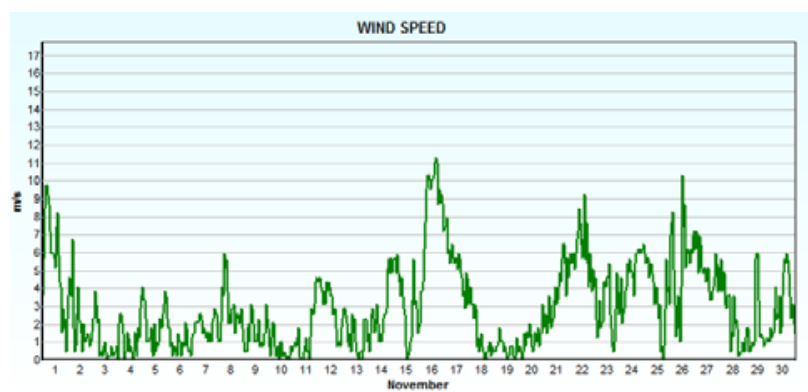

Fig. 7. Wind speed measured, November, 2003.

Another example: in 2005, the real effect of calmness is much harder, as there are about 14 days of calmness, between $4^{\text {th }}$ and $18^{\text {th }}$ January, 2005 (Fig. 8) so we must consider 14 consecutive days of calmness instead 5.7 .

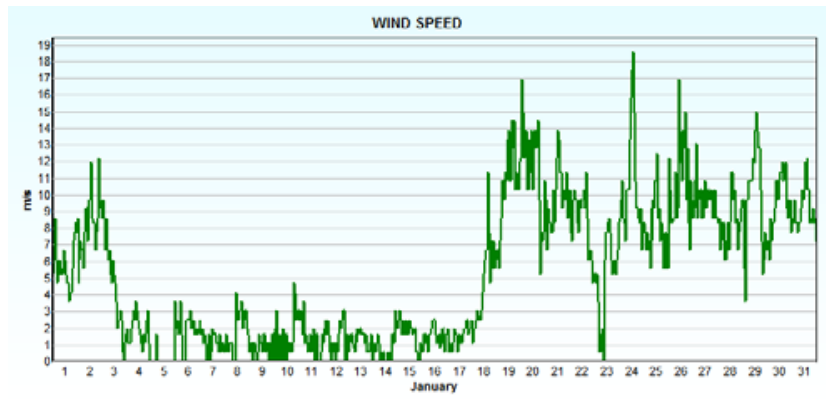

Fig. 8. Wind speed measured, January, 2005.

In Table II we can see that the results of the optimization using the measured wind speed hourly data form AEMET (type of data A) are very different from the results using the synthetically generated wind speed hourly data if no consecutive days of calmness is taken into account ( 0 consecutive days forced to have wind speed lower than 3 $\mathrm{m} / \mathrm{s}$, i.e., type of data B).
However, it can be seen that the results of the optimization using the synthetically generated wind speed hourly data taking into account the effective consecutive days of "calmness" for each year (type of data C) are quite similar to the ones obtained using the measured wind speed hourly data form AEMET (type of data A), even they are the same results the most of the cases.

In figures 9 and 10 it is shown, for the optimal system using wind speed data of year 2005 type A and using wind speed data type $C$ (both optimal systems have the same components), the total energy of the year (load, excess energy, wind turbines generation and batteries charge and discharge energy) and the hourly simulation during the whole year. The performance in the whole year of the system is very similar for both cases.

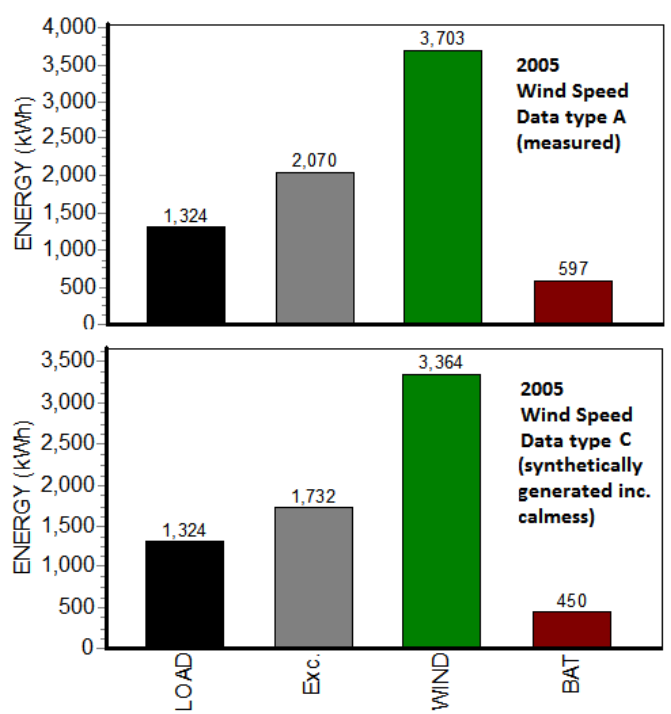

Fig. 9. Total energy during the whole year, optimal system, wind data 2005.

\section{Conclusions.}

The results show that, using monthly average wind speed data to generate synthetically wind speed hourly data of the year, if the number of consecutive days of forced calmness is adequate, the optimal system found by the optimization software tool is the same or very similar as the one obtained using the measured wind speed hourly data. Thus, the method of generating wind speed hourly data synthetically is validated to be used in the optimization of Wind-Batteries systems and therefore also in Wind-Hybrid systems.

However, if we use synthetically generated wind speed hourly data without considering an adequate number of days of calmness, the optimization using this data series obtains an optimal system very different form the obtained using the measured wind speed hourly data. 


\section{Acknowledgements.}

This work has been supported by the Spanish Government under the Investigation and Development (I+D) program number ENE2009-14582-C02-01.
Wind data yielded by the Spanish Meteorological Agency (Agencia Estatal de Meteorología, AEMET).

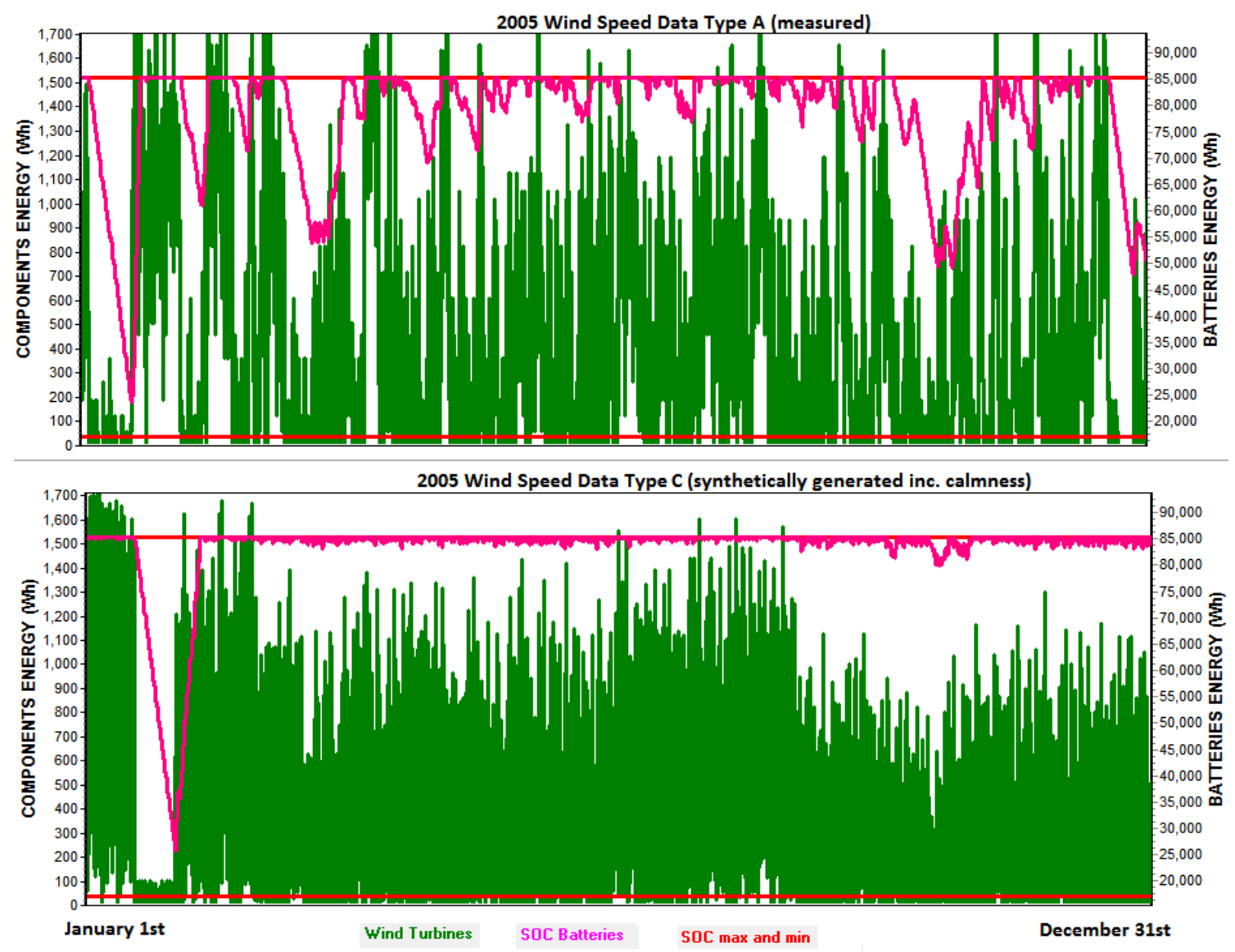

Fig. 10. Simulation of the optimal system. Wind data 2005.

\section{References.}

[1] Muselli, M., Notton, G., Louche, A., 1999. Design of Hybrid-Photovoltaic Power Generator, with Optimization of Energy Management. Solar energy 65(3), 143-157.

[2] Dufo-López, R., Bernal-Agustín, J.L., 2005. Design and control strategies of PV-Diesel systems using genetic algorithms. Solar Energy 79(1), 33-46.

[3] Dufo-López, R., Bernal-Agustín, J.L.,. HOGA (Hybrid Optimization by Genetic Algorithms) software. Free software available at www.unizar.es/rdufo.

[4] Brown B G, Katz R W, Murphy A H., 1984. Time series models to simulate and forecast wind speed and wind power. Journal of Climate and Applied Meteorology 23, 1184-1195.
[5] Dufo-López, R. Dimensionado y control óptimos de sistemas híbridos aplicando algoritmos evolutivos. PhD Disertation. University of Zaragoza, 2007.

[6] Agencia Estatal de Meteorología (Spanish Meteorological Agency), AEMET.

[7] Seguro, J.M., Lambert, T.W., 2000. Modern estimation of the parameters of the Weibull wind speed distribution for wind energy analysis. Journal of Wind Engineering and Industrial Aerodynamics $85,75-84$ 
Table II. - Optimizations for the wind speed of each year. Each year we have used 11 wind speed hourly series: 1 series measured and 10 sinthetically generated series.

\begin{tabular}{|c|c|c|c|c|c|c|c|c|c|}
\hline \multirow[b]{2}{*}{$\begin{array}{l}\text { Year } \\
\text { of } \\
\text { Data }\end{array}$} & \multirow[b]{2}{*}{$\begin{array}{l}\text { Type of Wind } \\
\text { Speed Data }\end{array}$} & & \multirow{2}{*}{$\begin{array}{c}\text { Number of } \\
\text { consecutive days } \\
\text { forced to have wind } \\
\text { speed }<3 \mathrm{~m} / \mathrm{s}\end{array}$} & \multicolumn{6}{|c|}{ OPTIMAL SYSTEM } \\
\hline & & & & $\begin{array}{l}\text { No. of } \\
\text { times }\end{array}$ & $\begin{array}{l}\text { NPC } \\
(€)\end{array}$ & $\begin{array}{l}\text { Wind } \\
\text { Turbines } \\
\text { (W) }\end{array}$ & $\begin{array}{l}\text { Batt. } \\
\text { Capacity } \\
\text { (Ah) }\end{array}$ & $\begin{array}{l}\text { Batt. } \\
\text { Cap. } \\
\text { (kWh) }\end{array}$ & $\begin{array}{c}\text { Days of } \\
\text { autho- } \\
\text { nomy }\end{array}$ \\
\hline \multirow{4}{*}{2001} & Measured & $\mathrm{A}$ & - & - & 22200 & $2 \times 1700$ & $4 \mathrm{sx} 1 \mathrm{px} 444$ & 21.3 & 3.75 \\
\hline & \multirow{3}{*}{$\begin{array}{l}\text { Synthetically } \\
\text { generated }\end{array}$} & $\mathrm{B}$ & 0 & 5 & 17300 & $2 \times 1700$ & $4 \mathrm{sx} 2 \mathrm{px} 80$ & 7.7 & 1 \\
\hline & & \multirow{2}{*}{$\mathrm{C}$} & \multirow{2}{*}{4 in December } & 3 & 22200 & $2 \times 1700$ & 4sx1px444 & 21.3 & 3.75 \\
\hline & & & & 2 & 21600 & $1 \times 6500$ & $4 s \times 4 p x 80$ & 15.4 & 2 \\
\hline \multirow{5}{*}{2002} & Measured & A & - & - & 23800 & $1 \times 6500$ & 4sx1px444 & 21.3 & 3.75 \\
\hline & \multirow{4}{*}{$\begin{array}{l}\text { Synthetically } \\
\text { generated }\end{array}$} & \multirow{2}{*}{ B } & \multirow{2}{*}{0} & 4 & 17300 & $2 \times 1700$ & $4 \mathrm{sx} 2 \mathrm{px} 80$ & 7.7 & 1 \\
\hline & & & & 1 & 17700 & $1 \times 6500$ & 4sx1px80 & 3.8 & 0.5 \\
\hline & & \multirow{2}{*}{$\mathrm{C}$} & \multirow{2}{*}{5 in December } & 4 & 23800 & $1 \times 6500$ & 4sx1px444 & 21.3 & 3.75 \\
\hline & & & & 1 & 22100 & $2 \times 1700$ & $4 \mathrm{sx} 1 \mathrm{px} 444$ & 21.3 & 3.75 \\
\hline \multirow{4}{*}{2003} & Measured & $\mathrm{A}$ & - & - & 28200 & $1 \times 6500$ & 4 sx9px80 & 34.6 & 4.6 \\
\hline & \multirow{3}{*}{$\begin{array}{l}\text { Synthetically } \\
\text { generated }\end{array}$} & $\mathrm{B}$ & 0 & 5 & 17300 & $2 \times 1700$ & $4 \mathrm{sx} 2 \mathrm{p} \times 80$ & 7.7 & 1 \\
\hline & & \multirow{2}{*}{$\mathrm{C}$} & \multirow{2}{*}{8 in November } & 4 & 28200 & $1 \times 6500$ & 4 sx9px80 & 34.6 & 4.6 \\
\hline & & & & 1 & 29600 & $2 \times 1700$ & $4 \mathrm{sx} 2 \mathrm{px} 444$ & 42.6 & 7.5 \\
\hline \multirow{5}{*}{2004} & Measured & $\mathrm{A}$ & - & - & 29600 & $2 \times 1700$ & 4 sx2px444 & 42.6 & 7.5 \\
\hline & \multirow{4}{*}{$\begin{array}{l}\text { Synthetically } \\
\text { generated }\end{array}$} & \multirow{2}{*}{ B } & \multirow{2}{*}{0} & 2 & 17300 & $2 \times 1700$ & $4 \mathrm{sx} 2 \mathrm{px} 80$ & 15.4 & 2 \\
\hline & & & & 3 & 16200 & $2 \times 1700$ & 4sx1px80 & 3.8 & 0.5 \\
\hline & & & & 4 & 29600 & $2 \times 1700$ & 4sx2px444 & 42.6 & 7.5 \\
\hline & & $\mathrm{C}$ & 9 in November & 1 & 29500 & $1 \times 6500$ & 4sx10px80 & 38.4 & 5.1 \\
\hline & Measured & $\mathrm{A}$ & - & - & 38500 & $1 \times 1700$ & $4 \mathrm{sx} 4 \mathrm{px} 444$ & 85.2 & 15 \\
\hline 2005 & Synthetically & $\mathrm{B}$ & 0 & 5 & 11200 & $1 \times 1700$ & $4 \mathrm{sx} 2 \mathrm{px} 80$ & 7.7 & 1 \\
\hline & generated & $\mathrm{C}$ & 14 in January & 5 & 38500 & $1 \mathrm{x} 1700$ & 4sx4px444 & 85.2 & 15 \\
\hline & Measured & $\mathrm{A}$ & - & - & 29500 & $1 \times 6500$ & 4sx10px80 & 38.4 & 5.1 \\
\hline & & & & 2 & 17300 & $2 \times 1700$ & $4 \mathrm{sx} 2 \mathrm{p} \times 80$ & 7.7 & 1 \\
\hline 2006 & Synthetically & B & 0 & 3 & 16200 & $2 \times 1700$ & 4sx1px80 & 3.8 & 0.5 \\
\hline & generated & $C_{1}$ & O. Donambr & 3 & 29500 & $1 \times 6500$ & 4sx10px80 & 38.4 & 5.1 \\
\hline & & C & 8 in December & 2 & 28200 & $1 \times 6500$ & 4sx9px80 & 34.6 & 4.6 \\
\hline & Measured & $\mathrm{A}$ & - & - & 29500 & $1 \times 6500$ & 4sx10px80 & 38.4 & 5.1 \\
\hline & & & & 3 & 17700 & $1 \times 6500$ & 4sx1px80 & 3.8 & 0.5 \\
\hline & & B & 0 & 1 & 17300 & $2 \times 1700$ & 4 sx2px80 & 7.7 & 1 \\
\hline 2007 & Synthetically & & & 1 & 18600 & $2 \times 1700$ & 4 sx3px80 & 11.5 & 1.5 \\
\hline & generated & & & 2 & 29500 & $1 \times 6500$ & 4sx10px80 & 38.4 & 5.1 \\
\hline & & $\mathrm{C}$ & 8 in April & 2 & 28200 & $1 \times 6500$ & 4sx9px80 & 34.6 & 4.6 \\
\hline & & & & 1 & 26900 & $1 \times 6500$ & 4 sx8px80 & 30.7 & 4.1 \\
\hline & Measured & $\mathrm{A}$ & - & - & 23800 & $1 \times 6500$ & $4 \mathrm{sx} 1 \mathrm{px} 444$ & 21.3 & 3.75 \\
\hline & & & & 4 & 19000 & $1 \times 6500$ & $4 \mathrm{sx} 2 \mathrm{px} 80$ & 7.7 & 1 \\
\hline 2008 & & B & 0 & 1 & 17700 & $1 \times 6500$ & 4sx1px80 & 3.8 & 0.5 \\
\hline & generated & & & 4 & 23800 & $1 \times 6500$ & $4 \mathrm{sx} 1 \mathrm{px} 444$ & 21.3 & 3.75 \\
\hline & & $\mathrm{C}$ & 4 in December & 1 & 23000 & $1 \times 6500$ & $4 \mathrm{sx} 5 \mathrm{p} \times 80$ & 19.2 & 2.5 \\
\hline & Measured & $\mathrm{A}$ & - & - & 23800 & $1 \times 6500$ & 4sx1px444 & 21.3 & 3.75 \\
\hline & & & & 4 & 11200 & $1 \times 1700$ & $4 \mathrm{sx} 2 \mathrm{px} 80$ & 7.6 & 1 \\
\hline 2009 & Synthetically & B & 0 & 1 & 10300 & $1 \times 1700$ & 4 sx1px80 & 3.8 & 0.5 \\
\hline & & $\mathrm{C}$ & 5 in February & 5 & 20400 & $1 \mathrm{x} 1700$ & 4 sx9px80 & 34.6 & 4.6 \\
\hline
\end{tabular}

